\title{
Serum iron markers in HIV and HIV-malaria infected participants residing in malaria endemic area of South-Eastern Nigeria
}

\author{
Charles O. CHINEDUM ${ }^{1 *}$, Frances E. CHIDIEBERE ${ }^{1}$, Rosemary A. ADAMMA ${ }^{2}$,
} Samuel M. CHUKWUEMEKA ${ }^{3}$, Anthony IGWEGBE ${ }^{4}$, Martins O. IFEANYICHUKWU ${ }^{1}$, Michael E. CHUKWUDI ${ }^{5}$, Amobi ILIKA ${ }^{6}$, Chike OKONKWO $^{3}$ and Daniel ANYIAM ${ }^{7}$

${ }^{l}$ Department of Medical Laboratory Science;

${ }^{2}$ Department of Chemical Pathology;

${ }^{3}$ Department of Human Biochemistry;

${ }^{4}$ Department of Obstetric and Gynaecology;

${ }^{5}$ Department of Immunology;

${ }^{6}$ Department of Community Medicine;

${ }^{7}$ Department of Histopathology, College of Health Sciences, Nnamdi Azikiwe University, Nnewi Campus, Nigeria.

"Corresponding author; E-mail: charleschinedum2002@yahoo.com

\begin{abstract}
HIV and malaria co-infections affect iron status. The present study was designed to determine the collective predictive power of some iron markers in HIV infected and malaria co-infected participants. For this study, 101 participants were randomly recruited from indivividuals requesting for HIV screening. The participants were grouped as 'asymptomatic HIV participants $(n=36)$; asymptomatic HIV-malaria co-infected participants $(n=19)$; symptomatic HIV participants $(n=16)$ and HIV uninfected control participants $(n=30)$. Blood analysis were performed for HIV infection, malaria infection, haemoglobin ( $\mathrm{g} / \mathrm{dl}), \mathrm{CD} 4+\mathrm{T}$ cell count $\left(/ \mathrm{mm}^{3}\right)$, albumin $(\mathrm{g} / \mathrm{l})$, iron $(\mathrm{ug} / \mathrm{dl})$, UIBC (ug/dl), TIBC (ug/dl) and percent transferrin saturation (TS\%). The analysis of variance (ANOVA) showed that the blood concentrations of haemoglobin $(\mathrm{f}=4.805, \mathrm{p}<0.01)$, iron $(\mathrm{f}=32.368, \mathrm{p}<0.01)$, TIBC $(\mathrm{f}=20.467, \mathrm{p}<0.01), \mathrm{TS} \%(\mathrm{f}=7.616, \mathrm{p}<0.01)$ and albumin $(\mathrm{f}=16.150, \mathrm{p}<0.01)$, were significantly different amongst the groups. The serum albumin, iron, TIBC and TS\% were significantly lowered in asymptomatic HIV, asymptomatic HIV-malaria co-infected and symptomatic HIV participants compared respectively with corresponding parameter in the control participants $(\mathrm{p}<0.01)$. The $\mathrm{CD} 4^{+} \mathrm{T}$ cell count was significantly lowered in symptomatic HIV participants compared with asymptomatic HIV participants with or without malaria co-infection $(\mathrm{p}<0.01)$. The study suggests that iron status may be affected in HIV infected individuals. The implications of the result are discussed.

(C) 2010 International Formulae Group. All rights reserved.
\end{abstract}

Keywords: Anaemia, viral, Plasmodium, co-infected.

\section{INTRODUCTION}

Significant number of individuals residing in sub-Saharan Africa have been shown to be HIV and malaria infected (Cohen et. al., 2005; Abu-Raddad et al., 2006;
Onyenekwe et al., 2007). HIV and malaria are known independently to contribute to high prevalence of anaemia in infected individuals (Onyenekwe et al., 2005; Onyenekwe et al., 2008; Ukibe et al., 2010). Routine 
investigation for anaemia in Nigeria and subsaharan Africa is by examination of blood film pictures, packed cell volume and haemoglobin concentration except in some Health institutions where facility and personnel is available, additional test for iron markers are added. It has been suggested that for meaningful interpretation of iron status in human, the following iron markers are of importance: haemoglobin, PCV, serum iron, TIBC, UIBC and percent transferri saturation (Kasvosve \& Delanghe, 2002; Yamanishi et al., 2003; Nwafia et al., 2006; AACC, 2009). In our earlier study, we relied on serum iron and PCV to define the iron status of HIV infected participants (Onyenekwe et al., 2008; Ukibe et al., 2010). We did not observe any significant difference in PCV between the HIV infected participants with or without malaria co-infection but we observed significant difference in serum iron level. The study thus showed the need to include other markers for defining anaemia and iron deficiency in HIV and HIV-malaria coinfections. Hence the present study was designed to determine the collective predictive power of some iron markers in establishing the presence of anaemia in HIV infected individuals using serum iron, haemoglobin, TIBC, UIBC and percent transferrin saturation.

\section{MATERIALS AND METHODS} Subjects

101 participants were randomly recruited for the present study among individuals reporting for voluntary HIV screening at the Voluntary Counseling Unit (VCT) of the Nnamdi Azikiwe University Teaching Hospital, Nnewi. After screening for HIV infection, 71 of the participants were HIV infected while 30 participants were HIV uninfected control participants. The participants were thereafter screened for Plasmodium falciparum malaria infection to establish HIV participants with malaria coinfection. The WHO classification for staging HIV/AIDS was used to classify the HIV participants into asymptomatic HIV infected and symptomatic (stage 2) HIV infected. The asymptomatic HIV infected $(n=55)$ were subdivided into asymptomatic HIV alone ( $\mathrm{n}=$ 36) and asymptomatic HIV with malaria coinfection $(n=19)$ while the symptomatic HIV infected participants $(n=16)$ are without malaria co-infection. $5 \mathrm{ml}$ of blood sample were collected from all the participants for the determination of CD4 $+\mathrm{T}$ cell count, serum albumin, haemoglobin, serum iron, TIBC, UIBC and percent transferrin saturation. The study design was approved by the ethical committee while the participants gave informed consent.

\section{Methods}

Method for HIV screening and method for the detection of Plasmodium falciparum histidine rich protein-2 seroreactivity and method for determination of $\mathrm{CD} 4+\mathrm{T}$ cell count by Cyflow SL Green were as previously described by Onyenekwe et al. (2006). The Bromocresol Green (BCG) method was used to determine serum albumin concentration while the Haemoglobin concentration was determined by Cyanomethaemoglobin method.

\section{Detection of serum iron, UIBC and TIBC}

The serum iron, UIBC and TIBC were determined using the ferrozine method. The procedure for the determination of serum iron, UIBC and TIBC was as described by the manufacturer of the iron/TIBC reagent (TECO Diagnostic, Anaheim, USA). The under listed formula was now used to calculate serum iron, UIBC and TIBC:

Serum iron (ug/dl): $\left[A_{2} T-A_{l} T / A_{2} S-A_{l} S\right] x$ conc. of STD UIBC $(u g / d l)=$ Conc. of STD $\left(A_{2}\right.$ test $-A_{1}$ test $) /\left(A_{2} S-A_{1} S\right) \times$ Conc. of STD/ 1 TIBC ug/dl = serum iron concentration + UIBC Percent transferrin saturation (TS\%) was calculated using: $\mathrm{TS} \%$ = serum iron/TIBC x 100 .

\section{Statistical analysis}

The variables were expressed as mean \pm standard deviation. Using the SPSS statistical package Student T-test was used to 
determine significant difference in mean between groups while ANOVA was used to determine the significant difference amongst the groups. $\mathrm{P}<0.05$ was considered significant.

\section{RESULTS}

The mean $( \pm \mathrm{SD})$ blood concentration of $\mathrm{CD} 4+\mathrm{T}$ cell count $\left(/ \mathrm{mm}^{3}\right)$ in asymptomatic HIV participants $(416 \pm 136)$, in asymptomatic HIV malaria co-infected participants $(439 \pm 172)$ and symptomatic HIV participants $(113 \pm 58)$ were significantly different $(\mathrm{F}=31.342 ; \mathrm{P}<0.01)$. The mean CD4+ T cell counts were significantly higher in asymptomatic HIV and symptomatic HIV malaria co-infected compared with the symptomatic HIV $(\mathrm{P}<0.01$ in each case $)$ (Table 1).

The means $( \pm \mathrm{SD})$ haemoglobin concentration $(\mathrm{g} / \mathrm{dl})$ in asymptomatic HIV participants $(11.7 \pm 2.1)$, in asymptomatic HIV malaria co-infected participants $(11.6 \pm 1.1)$, in symptomatic HIV participants $(9.9 \pm 1.8)$ and control participants $(11.5 \pm 1.1)$ were significantly different $(\mathrm{F}=4.305 ; \mathrm{P}<0.01)$. The mean concentration of haemoglobin was significantly lower in symptomatic HIV participants compared with asymptomatic and control participants respectively $(\mathrm{P}<0.01$ in each case) (Table 1).

The mean $( \pm \mathrm{SD})$ serum iron concentration (ug/dl) in asymptomatic HIV participants $(90.66 \pm 50.1)$, in asymptomatic HIV-malaria co-infected participants (92.8 \pm 34.0$)$, in symptomatic HIV participants $(75.5 \pm 45.1)$ and control participants $(210 \pm 78.9)$ were significantly different $(\mathrm{F}=$ 32.368; $\mathrm{p}<0.01$ ). between group comparism showed that the serum iron concentration was significantly lower in both asymptomatic HIV with or without malaria and symptomatic HIV participants compared with corresponding parameter in control participants (Table 1).

The mean $( \pm \mathrm{SD})$ serum UIBC concentration $(\mathrm{ug} / \mathrm{dl})$ in asymptomatic HIV participants (197.1 \pm 76.7$)$, in asymptomatic HIV-malaria co-infected participants
(235.2 \pm 63.5$), \quad$ in symptomatic HIV participants $(189.0 \pm 108.9)$ and control participants $(243.9 \pm 112.5)$ were significantly different $(\mathrm{F}=2.153 ; \mathrm{P}>0.05)$ (table 1$)$.

The means $( \pm \mathrm{SD})$ serum TIBC concentration (ug/dl) in asymptomatic HIV participants $(288.2 \pm 71.9)$, in asymptomatic HIV-malaria infected participants (328.0 \pm 62.0), in symptomatic HIV participants (264.5 \pm 93.4$)$ and control participants $(444.3 \pm 122.5)$ were significantly different $(\mathrm{F}=20.467 ; \quad \mathrm{p}<0.01)$. The mean serum concentration of TIBC was significantly lower in asymptomatic HIV with or without malaria co-infection and symptomatic HIVparticipants compared with control participants $(\mathrm{P}<0.01$ in each case) (Table 1).

The mean \pm SD serum $\mathrm{TS} \%$ in asymptomatic HIV participants (32.9 \pm 19.1$)$, in asymptomatic HIV-malaria infected participants $(28.9 \pm 11.6)$, in symptomatic HIV $(31.2 \pm 21.4)$ and control participants $(50.2 \pm 18.8) \quad$ were significantly different $(\mathrm{F}=7.616 ; \mathrm{P}<0.01)$. However, the mean TS\% was significantly lower in asymptomatic HIV with or without malaria co-infection and symptomatic HIV participants compared with control participants $(\mathrm{P}<0.01$ in each case) (See Table 1).

The mean $( \pm \mathrm{SD})$ serum albumin concentration $(\mathrm{g} / \mathrm{l})$ in asymptomatic HIV participants (34.6 \pm 3.3$)$, in asymptomatic HIVmalaria co-infected participants $(33.5 \pm 3.4)$, in symptomatic HIV participant $(28.6 \pm 7.5)$ and control participants $(37.6 \pm 3.3)$ were significantly different $(\mathrm{F}=16.150 ; \mathrm{P}<0.01)$. The mean concentration of serum albumin was significantly lower in symptomatic HIV participants compared with either the asymptomatic HIV with or without malaria co-infection and control participants respectively ( $\mathrm{P}<0.01$ in each case) (Table 1$)$.

There was a significant positive association between the $\mathrm{CD}^{+} \mathrm{T}$ cell count and serum haemoglobin concentration in the symptomatic HIV participants $(r=0.629$, $\mathrm{P}<0.01)$. 
Table 1: Mean \pm SD CD4+T cell count $\left(/ \mathrm{mm}^{3}\right), \mathrm{Hb}(\mathrm{g} / \mathrm{dl})$, iron (ug/dl), UIBC (ug/dl), TIBC (ug/dl), $\mathrm{TS} \%$ and albumin $(\mathrm{g} / \mathrm{dl})$ in asymptomatic HIV, asymptomatic HIV-MP, symptomatic HIV and control participants.

\begin{tabular}{llllllll}
\hline Parameters & CD4 & Hb & iron & UIBC & TIBC & TS\% & Albumin \\
\hline $\begin{array}{l}\text { Asymptomatic } \\
\text { HIV (n=36)[a] }\end{array}$ & $416 \pm 136$ & $11.7 \pm 2.1$ & $90.6 \pm 50.1$ & $197.1 \pm 76.7$ & $288.2 \pm 71.9$ & $32.9 \pm 19.1$ & $34.6 \pm 3.3$ \\
\hline Asymptomatic & $439 \pm 172$ & $11.6 \pm 1.1$ & $92.8 \pm 34.0$ & $235.2 \pm 63.5$ & $328.0 \pm 62.0$ & $28.9 \pm 11.6$ & $33.5 \pm 3.4$ \\
HIV-MP & & & & & & & \\
(n=19)[b] & & & & & & & \\
\hline Symptomatic & $113 \pm 58$ & $9.9 \pm 1.8$ & $75.5 \pm 45.1$ & $189.0 \pm 108.9$ & $264.5 \pm 93.4$ & $31.2 \pm 21.4$ & $28.6 \pm 7.5$ \\
HIV (n=16)[c] & & & & & & & \\
\hline Control & - & $11.5 \pm 1.1$ & $210.4 \pm 78.9$ & $243.9 \pm 112.5$ & $444.3 \pm 122.5$ & $50.2 \pm 18.8$ & $37.6 \pm 3.3$ \\
(n=30)[d] & & & & & & & \\
\hline F -value & 31.342 & 4.805 & 32.368 & 2.153 & 20.467 & 7.616 & 16.150 \\
P-value & $<0.01$ & $<0.01$ & $<0.01$ & $>0.05(\mathrm{~ns})$ & $<0.01$ & $<0.01$ & $<0.01$ \\
[a] vs [b] & $>0.1(\mathrm{~ns})$ & $>0.1(\mathrm{~ns})$ & $>0.1(\mathrm{~ns})$ & $>0.05(\mathrm{~ns})$ & $<0.05$ & $>0.1(\mathrm{~ns})$ & $>0.1(\mathrm{~ns})$ \\
[a] vs [c] & $<0.01$ & $<0.01$ & $>0.1(\mathrm{~ns})$ & $>0.1(\mathrm{~ns})$ & $>0.1(\mathrm{~ns})$ & $>0.1(\mathrm{~ns})$ & $<0.01$ \\
[a] vs [d] & $\mathrm{Nc}$ & $>0.1(\mathrm{~ns})$ & $<0.01$ & $=0.05$ & $<0.01$ & $<0.01$ & $<0.01$ \\
[b] vs [c] & $<0.01$ & $<0.01$ & $>0.1(\mathrm{~ns})$ & $>0.1(\mathrm{~ns})$ & $<0.05$ & $>0.1(\mathrm{~ns})$ & $<0.05$ \\
[b] vs [d] & $\mathrm{nc}$ & $>0.1(\mathrm{~ns})$ & $<0.01$ & $>0.1(\mathrm{~ns})$ & $<0.01$ & $<0.01$ & $<0.01$ \\
[c] vs [d] & $\mathrm{nc}$ & $<0.01$ & $<0.01$ & $>0.1(\mathrm{~ns})$ & $<0.01$ & $<0.01$ & $<0.01$ \\
\hline
\end{tabular}

$\mathrm{nc}=$ not compared, $\mathrm{ns}=$ not significant

\section{DISCUSSION}

The present study observed that the serum iron concentration, TIBC and TS\% were all affected by HIV infection and HIVmalaria co-infection while haemoglobin concentration was additionally affected only in the symptomatic HIV infected participants. The above serum markers, of iron seemed consistent and could give a better understanding of how HIV and HIV-malaria co-infections affects the iron status of individuals. Using the above iron markers their presentation suggest aneamia of chronic disease for both the asymptomatic HIV participants and symptomatic HIV participants while a mixture of both anaemia of iron deficiency and of chronic disease was presented by asymptomatic HIV-malaria coinfected participants.

HIV infection is a chronic disease with no present cure while infections with Plasmodium falciparum are curable. Studies elsewhere showed no difference in serum iron concnetration between apparently healthy individuals and parasitaemic individuals (Das et al., 1997; Odunukwe et al., 2000). Ukibe et al. (2010) have shown that the serum iron and PCV was significanlty lower in HIV infected subjects with or without malaria compared with corresponding parameter in HIV uninfected subjects. They also observed no significant difference in serum iron concentration and PCV between symtomatic HIV infected and symptomatic HIV malaria co-infected and between asymptomatic HIV infected and asymptomatic HIV malaria coinfected.

In the present study, between the asymptomatic HIV infected and asymptomatic HIV-malaria co-infected participants, only the TIBC level was significantly different. This is also the case between asymptomatic HIVmalaria co-infected and symptomatic HIV participants. Furthermore, haemoglobin concentration was significantly lower in symptomatic HIV compared with 
asymptomatic HIV with or without malaria co-infection. The addition of TIBC in the present study as one of the iron markers, unlike in our previous studies has helped to show some level of differences in iron status within the HIV categories.

In our previous study of symptomatic $\mathrm{HIV}$ individuals with mean $\mathrm{CD} 4+\mathrm{T}$ cell counts above 200 cells per $\mathrm{mm}^{3}$ and PCV of 0.31 (1/1) (Onyenekwe et al., 2008) the mean serum iron was higher compared with the mean serum iron observed in the present study of symptomatic HIV participants with CD4 + $\mathrm{T}$ cell count of less than 200 cell per $\mathrm{mm}^{3}$. The CD $4^{+} \mathrm{T}$ cell count is a good marker used to ascertain the level of recovery or progression of HIV/AIDS. Using these profiles of iron markers and CD4 $+\mathrm{T}$ cell count, it is possible that the iron status of HIV infected individuals changes with progression or recovery.

Both serum albumin concentration and CD4 ${ }^{+} \mathrm{T}$ cell count have been used to define presentation of HIV in infected individuals (Feldman et al., 2003; Olawumi and Olutunji, 2006; Onyenekwe et al., 2006). CD4+ T cell below 200 cells per mm3 has been shown to predispose to HIV/AIDS, while reduced serum albumin has also been used to define prognosis in HIV infected individuals. (Olawumi and Olutunji, 2006).

The present study was able to use collective ability of the iron markers to show differences in iron status. It also showed that the anaemia was predominantly caused by HIV. The abilty of the individual iron markers to indicate deleterious effect of HIV in different stages of HIV helped to reveal the existence of distorted iron status.

\section{REFERENCES}

American Association for Clinical Chemistry (AACC). 2009. "TIBC, UIBC, Transferrin". http://www.labtestsonline. org/undeertanding/analytes/tibc/test.html.
Abu- Raddad LJ, Patnaik P, Kublin JG, 2006. Dual infection with HIV and malaria fuels the spread of both diseases in subsaharan Africa. Science, 315(5812): 598.

Das BS, Thumham DI, Das DB. 1997. Influence of malaria on markers of iron status in children: implications for interpreting iron status in malaria endemic communities. Br. J. Nutr., 78(5); 751-760.

Cohen C, Karstaedt A, Frean J, Thomas J, Govender N, prentice E, Dini L, Galpin J, Crewe-Brown H. 2005. Increased prevalence of severe malaria in HIinfected adults in South Africa. Clin. Infect. Dis., 41(11): 1631-1637.

Feldman JG, David N, Urns M, Gange SJ. 2003. Serum albumin is apowerful predictor of survival among HIV-1 infected women. J. AIDS, 33: 66-73.

Kasvosve I, Delanghe J. 2002. Total iron binding capacity and transferrin concentration in the assessment of iron status. Clin. Chem. Lab. Med., 40(10): 1014-1018.

Nwafia WC, Aneke JO, Okonji CU. 2006. Serum iron and total iron binding capacity levels among the ABO Blood groups in Enugu South Eastern Nigeria. Nigerian Journal of Physiological Sciences, 21(1-2): 9-14.

Olawumi HO, Olatunji PO. 2006. The value of serum albumin in pre-treatment assessment and monitoring of therapy in HIV/AIDS patients. HIV Med., 7: 357355.

Odunukwe NN, Salako LA, Okany C, Ibrahim MM. 2000. Serum ferritin and other haematological measurement in apparently healthy adults with malaria parasitaemia in Lagos, Nigeria. Trop. Med. Int. Health, 5(8): 582-586.

Onyenekwe CC, Meludu SC, Arinola OG, Salimonu LS. 2005. Relationships between $P$. falciparum density, haptoglobin, transferrin and packed cell 
volume in apparently healthy pregnant women. African Journal of Biomedical Research, 8(1): 21-24.

Onyenekwe CC, Ezeugwunne IP, Meludu SC, Ilika A, Igwegbe AO, Ukibe RN. 2006. Urinary ascorbic acid and serum concentrations of circulating immune complexes and albumin in HIV infected subjects. J. Biomedical Investigation, 4(2): 54-59.

Onyenekwe CC, Ukibe N, Meludu SC, Ilika A, Aboh N, Ofiaeli N, Ezeani M, Onochie A. 2007. Prevalence of malaria as co-infection in HIV-infected individuals in a malaria endemic area of Southeastern Nigeria. J. Vector Borne Dis., 44: 250-254.

Onyenekwe CC, Ukibe N, Meludu SC, Ifeayi $\mathrm{M}$, ezeani $\mathrm{M}$, Onochie A, Ofiaeli $\mathrm{N}$, Aboh A, Ilika A. 2008. Possible biochemical impact malaria infection in subjects with HIv co-infection in Anambra State, Nigeria. J. Vector Borne Disease, 45; 151-156.

Ukibe NR, Onyenekwe CC, Ahaneku JE, Meludu SC, Ukibe SN, Ilika A, Ifeanyi M, Igwegbe AO, Ezeani M, Onochie A, Ofiaeli N. 2010. Packed cell volume and serum iron in subjects with HIV-malaria co-infection in nnewi, South-eastern Nigeria. Int. J. Biol. Chem.. Sci., 4(2): 471-478.

Yamanishi H, Iyama S, Yamaguchi Y, kanakura Y, Iwatani Y. 2003. Total iron binding capacity calculated from serum transferrin concentration or serum iron concentration and unsaturated ironbinding capacity. Clin. Chem., 49(1): 175-178. 